\title{
Prevalence, short term outcome and factors associated with survival in patients suffering from upper gastrointestinal bleeding in a resource limited-setting, the case of Mulago hospital in Kampala, Uganda
}

\author{
Serge Kahatwa Kiringa ${ }^{1}$, Jacklyn Quinlan ${ }^{2,3}$, Ponciano Ocama ${ }^{1}$, Innocent Mutyaba ${ }^{1}$, Magid Kagimu ${ }^{1}$
}

1. Makerere University, school of Health Sciences, Department of Medicine, Gastroenterology unit Mulago Hospital, Kampala, Uganda.

2. Genetics Institute, University of Florida, Gainesville, FL.

3. Department of Anthropology, University of Florida, Gainesville, FL.

\begin{abstract}
Background: Upper gastrointestinal bleeding (UGIB) is a common cause of admission and death in the gastroenterology service. The prevalence, risk factors and the case fatality rate of UGIB may differ by settings.

Objectives: Our objective was to determine the prevalence of symptoms and the case fatality rate of UGIB among patients at the gastroenterology service of Mulago Hospital in Kampala, Uganda and to describe the clinical and laboratory risk factors associated with the survival of these patients.

Methods: In a cross-sectional study performed between September 2013 and April 2014,

patients were screened for UGIB symptoms. Data was collected on socio-demographic characteristics, clinical presentation and patient's outcome within one week of admission. Bivariate, multivariate, and survival analysis were performed to identify variables that were significantly associated with mortality.

Results: Out of 1085 patients screened, we identified the prevalence of UGIB symptoms in 220 patients (20.3\%). Among these, 150 met the inclusion criteria for our study. The majority were males $(70.7 \%)$ and 40 years of age or less $(60 \%)$. The most prevalent clinical diagnosis were gastritis (39.3\%), esophageal varices (17.3\%) and peptic ulcer disease (PUD) (16\%). Among patients who underwent endoscopy, esophageal varices $(42.2 \%)$, PUD $(26.3 \%)$ and gastritis $(15.8 \%)$ were the leading causes of bleeding. The overall case fatality rate was $16.7 \%(25 / 150)$. Uremia remained associated with mortality after controlling for confounders.

Survival was significantly reduced for males as well as for patients with uremia and malignancy.

Conclusion: the prevalence of symptoms and the case fatality rate of UGIB among patients admitted to the gastroenterology ward in Mulago hospital were higher than in developed countries and similar to other resource-limited setting. The majority of patients were young men and presented with both hematemesis and melena. The most common causes of UGIB were esophageal varices, gastritis and PUD. Survival analysis indicate that male gender, uremia, and malignancy are associated with reduced survival.
\end{abstract}

Keyword: Upper gastrointestinal bleeding, gastroenterology, survival, Uganda, Africa.

DOI: https://dx.doi.org/10.4314/ahs.v20i1.49

Cite as: Kiringa SK, Quinlan J, Ocama P, Mutyaba I, Kagimu M. Prevalence, short term outcome and factors associated with survival in patients suffering from upper gastrointestinal bleeding in a resource limited-setting, the case of Mulago hospital in Kampala, Uganda. Afri Health Sci. 2020;20(1):426-36. https:// dx.doi.org/10.4314/abs.v20i1.49

\section{Introduction}

Upper gastrointestinal bleeding (UGIB) is a major affliction worldwide and it is one of the most common patient presentation in gastroenterology ${ }^{1}$. It is associ-

\section{Corresponding author:}

Serge Kahatwa Kiringa,

Makerere University, school of Health Sciences,

Department of Medicine, Gastroenterology unit

Mulago Hospital, Kampala, Uganda.

Email: serge_luc@yahoo.fr ated with significant morbidity and mortality ${ }^{2}$. Well known causes of UGIB include duodenal ulcers (DU), gastric ulcers $(\mathrm{GU})$, erosive mucosal disease (EMD), esophageal varices due to portal hypertension (PHTN) and Mallory-Weiss syndrome (MWS). Hematemesis (the vomiting of blood) and melena (blood in feces causing it to be black) are the most common presenting symptoms of upper gastrointestinal hemorrhage. Patients who present with acute UGIB and a substantial loss of intravascular volume have signs and symptoms of shock. 
The annual worldwide incidence of hospitalization for UGIB is approximately one per thousand adult ${ }^{3}$. Over the last decade, the worldwide trend of mortality due to UGIB has not changed, varying between 3 to14 percent $^{3}$. However, there are significant differencesn mortality dependent on resource availability. In 2009, UGIB had an incidence of 146 per 100,000 per year and mortality rate of $3.1 \%$ in developed countries such as the USA $^{4}$. A hospital based study conducted between July 2004 and February 2005 in the USA on acute UGIB identified that $90.2 \%$ of patients with UGIB were discharged without complications. In resource-limited settings, the situation is different and the mortality tends to be higher. Among patients presenting for upper GI endoscopy at a referral hospital in Nigeria, 67.6\% were found to have peptic ulcer disease (PUD), 7\% were found to have gastric cancer and 6.9 were found to have upper gastrointestinal bleeding ${ }^{6}$. Two studies performed in Tanzania and in Nigeria reported a mortality rate of $17 \%$ for patients admitted with UGIB and found that male gender and age between 20 and 40 were risk factors for higher mortality ${ }^{7,8}$. A study in Northern Uganda found that esophageal varices were the most common cause of UGIB among adult patients who underwent endoscopy, with an equal proportion of males to females ${ }^{10}$.

The prevalence, risk factors and mortality associated with UGIB at Mulago hospital in Kampala, Uganda in adults is not known. Our objective was to better understand these factors in order to improve outcomes of patients with UGIB in this resource poor setting.

\section{Methods}

A cross sectional study was performed in which patients admitted to the gastrointestinal inpatient service of Mulago National Referral Hospital were recruited between September 10 ${ }^{\text {th }}, 2013$ and April 8 8 $^{\text {th }}, 2014$. The study population included all patients admitted to the gastroenterology ward during the study period who met the following inclusion criteria: adult patients aged 18 years or older who reported hematemesis and/or melena on admission. We excluded patients with: a) signs of generalized bleeding; b) patients with symptoms of melena with negative fecal occult blood test; c) patients with a history of ingestion of substances causing black discoloration of stool. Patients with generalized bleeding due to coagulopathy were excluded because they may vomit blood or have blood in stool when the origin is not from the GI tube (e.g.: swollen blood from epistaxis).
Socio-demographic characteristics, symptoms of UGIB and clinical signs at admission were recorded. Patients were followed from admission up to the seventh day of admission to evaluate their outcome (death or survival). The diagnoses from the attending doctor on the ward, the endoscopic diagnosis and results were also recorded. A questionnaire was administered to obtain study variables such as gender, age, residential location, and symptoms of UGIB. A physical examination was done to collect additional clinical variables, including blood pressure, pulsation, and the Glasgow coma scale (GCS). Low GCS was defined as $\leq 14$. Blood was drawn for a complete blood count (CBC), renal function tests (RFTs) and liver function tests (LFTs). Uremia was defined as urea of more than $6.5 \mathrm{mmol} / \mathrm{L}$ according to the cut off in the hospital laboratory.

Ethics approval was obtained from departement of medicine, Makerere University College of Health sciences as well as the School of Medicine, Research and Ethics Committee. Written informed consent was obtained from all participants in English or their local dialect (Luganda).

\section{Data analysis}

Data was entered using EpiData computer software (version 3.1) and transferred to Stata (version 12) for analysis. Univariate analysis was performed to obtain summary statistics and the results are presented in tables using frequencies and percentages.

The prevalence of UGIB was calculated using number of patients who reported symptoms of UGIB divided by the total number of patients admitted to the gastrointestinal ward from September 10 ${ }^{\text {th }}, 2013$ to April 8th, 2014, and expressed as a percentage. The case fatality rate among patients with UGIB was calculated by expressing the number of patients who died as a percentage of the total number of patients with UGIB studied. A p-value of $\leq 0.05$ was considered statistically significant.

Survival analyses were performed using Jmp/Genomics (version 7.0) SAS Institute Inc. (NC, USA) and the nonparametric Kaplan-Meier method was performed to examine difference in survival among patients who died and who were discharged. Differences that might occur between gender, uremia levels, diagnosis and GCS were further analyzed by grouping patients. Statistical differences between the mean numbers of days survived for each group were evaluated by the non-parametric Wilcoxon test implemented in Jmp/Genomics. 


\section{Results}

\section{Patient's flow chart}

One thousand and eighty-five (1085) patients admitted to the gastroenterology ward were screened for symptoms of UGIB and those with symptoms of UGIB were invited to take part in the study. Out of the two hundred and twenty patients who reported symptoms of UGIB, seventy (70) patients were excluded. Twenty-three (23) patients reported melena with negative
FOB, twenty-one (21) patients had generalized bleeding due to liver failure or other bleeding conditions, two (2) patients had vaginal bleeding, seven (7) patients admitted to the gastroenterology ward with complaints of UGIB died before screening, twelve (12) patients did not consent and five (5) patients were not followed up because they were transferred to other units due to comorbidities. This left a final number of one hundred fifty (150) patients enrolled in the detailed study (Figure $1)$.

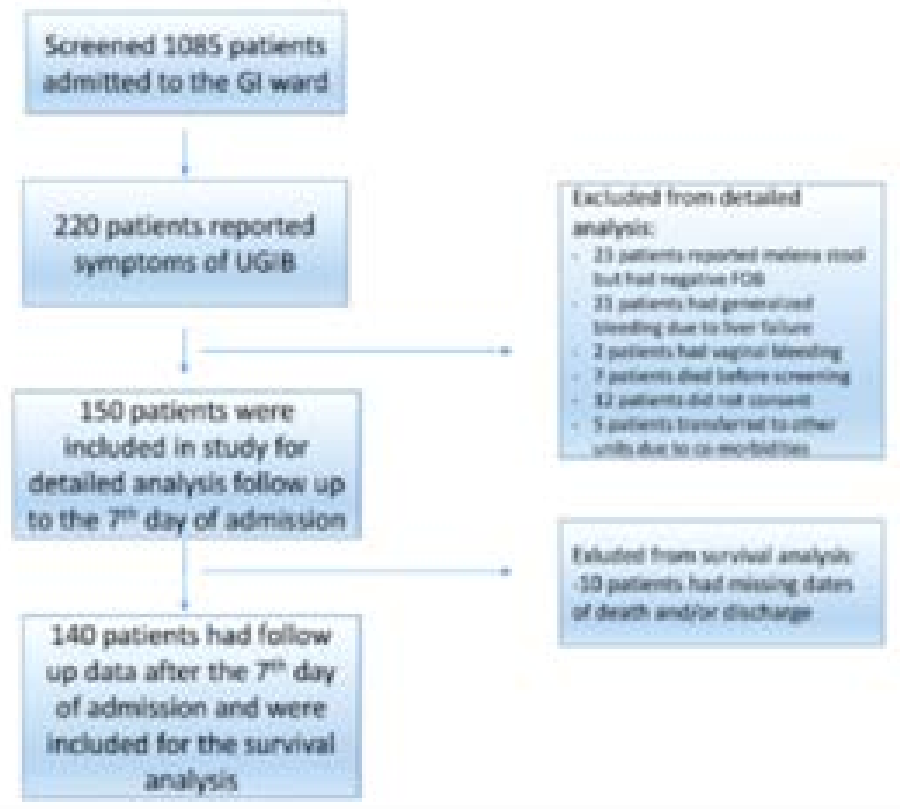

Figu re 1. Patient flow chart. Out of the 1085 patients that were screened, two hundred twenty patients reported symptoms of UGIIB and one hundred fifty patients met the study inclusion criteria.

\section{Socio demographic characteristics of study pa- tients.}

The median age was 38 years with a range from 18 to 89 years. Most (90/150) patients were 40 years of age or less. The proportion of males was higher than that of females (106 males versus 44 females). Most patients resided from places outside of Kampala city (66 living in Kampala: 84 living elsewhere), and the majority of patients were Christians (118 Christian: 32 other). Most patients earned less than 500,000 UGSHS (Ugandan shillings) per month $(141 / 150)$, which corresponds to less than 200 USD per month and is below the pover- ty line. Most patients were non-smokers (17 smokers versus 133 non-smokers) and most were non-alcohol consumers (44 alcohol consumers versus 106 non-alcohol consumers). Since endoscopy services in Kampala cost between UGSHS 200,000 and 700,000, few patients were able to pay for the endoscopy (38 out of 150). See Table 1 for a description of the socio-demographic characteristics of the study participants. There was no significant difference in the socio-demographic characteristics of the patients who had endoscopy and those who did not have endoscopy (See Supplemental Table 1). 
S1 Table. Chi square test for differences in socio-demographic characteristics among patients who had endoscopy versus patients who did not have endoscopy.

$\begin{array}{llllll}\text { Variables n (\%) } & \text { Endoscopy } & \text { No endoscopy } & \text { OR } & 95 \% \text { CI } & \text { p-value }\end{array}$

Age

$=40$ years $\quad 16(26.7) \quad 44(73.3)$

$\begin{array}{llllll}>40 \text { years } & 22(24.4) & 68(75.6) & 0.89 & 0.42-1.88 & 0.75\end{array}$

Gender

Male

27(25.7) 78(74.3)

Female

$11(25)$

$33(75)$

0.96

$0.43-2.17$

0.92

Home address

Out of Kampala

21(25)

63(75)

Kampala

17(25.8)

49(74.2)

0.96

$0.46-2.01$

0.92

Religion

Christian

28(23.7)

$90(76.3)$

No Christians

$10(32.3) \quad 21(67.7)$

1.24

$0.8-1.9$

0.33

Monthly income

$=500000$ UGSHs $\quad 34(24.3) \quad 106(75.7)$

$>500000$ UGSHs $\quad 4(44.4) \quad 5(55.6)$

$2.5 \quad 0.63-9.81$

0.19

Prevalence of symptoms of UGIB among study patients

The prevalence of symptoms of UGIB among patients in the gastroenterology ward was $20.3 \%(220 / 1085)$. The proportion of patients admitted with both he- matemesis (vomiting blood) and melena (blood in feces causing it to be black) was 105 out of 1085 (9.7\%), which was higher than that of patients admitted with hematemesis alone ( 62 out of $1085 ; 5.7 \%$ ) or with melena alone (53 out of 1085; 4.9\%) (Supplemental Table 2).

S2 Table. Prevalence of symptoms of upper gastrointestinal bleeding among patients admitted to the Gastroenterology ward in Mulago hospital. N= 1085

\begin{tabular}{lcc}
\hline Diagnosis & $\mathbf{n}$ & $\mathbf{\%}$ \\
$\begin{array}{l}\text { Patients with symptoms of Upper } \\
\text { gastrointestinal bleeding }\end{array}$ & 220 & 20.3 \\
$\quad$ Hematemesis alone & 62 & 5.7 \\
Melena alone & 53 & 4.9 \\
$\quad$ Hematemesis and Melena & 105 & 9.7 \\
Patients with other symptoms & 865 & 79.7 \\
\hline
\end{tabular}


Table 1. Socio-demographic characteristics of study participants $N=150$

\begin{tabular}{|c|c|c|c|}
\hline Characteristics & & $\mathbf{N}$ & $\%$ \\
\hline \multicolumn{4}{|l|}{ Age group } \\
\hline$=40$ & & 90 & 60 \\
\hline$>40$ & & 60 & 40 \\
\hline \multicolumn{4}{|l|}{ Gender } \\
\hline Male & & 106 & 70.7 \\
\hline Female & & 44 & 29.3 \\
\hline \multicolumn{4}{|l|}{ Home address } \\
\hline In Kampala & & 66 & 44 \\
\hline Out of Kampala & & 84 & 56 \\
\hline \multicolumn{4}{|l|}{ Religion } \\
\hline Muslim & & 31 & 20.7 \\
\hline Christian & & 118 & 78.7 \\
\hline Other & & 1 & 0.6 \\
\hline \multicolumn{4}{|l|}{ Monthly income } \\
\hline $\begin{array}{l}\text { Low income }(<500,000 \\
\text { month }) *\end{array}$ & UGSHS per & 141 & 94 \\
\hline $\begin{array}{l}\text { High income }(>500,000 \\
\text { month })\end{array}$ & UGSHS per & 9 & 6 \\
\hline \multicolumn{4}{|l|}{ Smoking } \\
\hline Yes & & 17 & 11.3 \\
\hline No & & 133 & 88.7 \\
\hline \multicolumn{4}{|l|}{ Alcohol consumption } \\
\hline Yes & & 44 & 29.3 \\
\hline No & & 106 & 70.7 \\
\hline
\end{tabular}

$* 1 U S D=3350$ UGSH (bank rate)

Frequency of clinically suspected causes of UGIB among study patients

The frequency of the provisional diagnoses of UGIB was calculated based on the diagnoses made by the doctors on the ward. Gastritis was the most frequent diagnosis made in 59/150 (39.3\%), followed by bleeding esophageal varices in 26/150 (17.3\%) and peptic ulcer disease in $24 / 150(16 \%)$. See Table 2 for the complete provisional diagnoses made for the 150 patients.
Frequency of endoscopically confirmed causes of UGIB

Thirty-eight patients could afford endoscopy, among them; bleeding varices were the most common cause of UGIB in 16/38 (42.2\%), followed by PUD in 10/38 $(26.3 \%)$ and gastritis in 6/38 (15.8\%). Malignancy, esophagitis and esophageal candidiasis were less frequent (see table 2). 
Table 2. Frequency of diagnosis (provisional or by endoscopy) of upper gastrointestinal bleeding among study patients

\begin{tabular}{|c|c|c|c|c|}
\hline Provisional diagnosis $(n=150)$ & $\mathrm{N}$ & & $\%$ & \\
\hline Gastritis & 59 & & 39.3 & \\
\hline Bleeding varices & 26 & & 17.3 & \\
\hline PUD & 24 & & 16 & \\
\hline Mallory Weiss tears & 16 & & 10.7 & \\
\hline Malignancy & 13 & & 8.7 & \\
\hline Esophagitis & 4 & & 2.7 & \\
\hline No definite diagnosis & 8 & & 5.3 & \\
\hline \multicolumn{5}{|l|}{ Endoscopic $\operatorname{diagnosis}(n=38)$} \\
\hline Bleeding varices & & 16 & & 42.2 \\
\hline PUD & 10 & & 26.3 & \\
\hline Gastritis & 6 & & 15.8 & \\
\hline Malignancy & 4 & & 10.5 & \\
\hline Esophagitis & 1 & & 2.6 & \\
\hline Esophageal candidiasis & 1 & & & 2.6 \\
\hline
\end{tabular}

Frequency of complications of UGIB among study patients.

Tachycardia was the most frequent complication followed by fainting and hypotension as signs of shock. Out of 132 patients admitted with laboratory results, 111/132 (84.1\%) were anemic, while 39.4\% (52/132) had severe anemia (hemoglobin $\leq 5 \mathrm{~g} / \mathrm{dl}$ ). Eleven percent $(17 / 150)$ of patients were admitted with a reduced GCS of less than 15. Among patients who had urea done, 44.6\% (49/109) had uremia. See Supplemental table 3 for description of the complications observed in the UGIB patients.

Table 3. Association between patients' characteristics and case fatality among study patients $(\mathrm{n}=150)$

\begin{tabular}{|c|c|c|c|c|c|}
\hline Variables & Outcome & & OR & $95 \% \mathrm{CI}$ & $\begin{array}{l}\text { p- } \\
\text { value }\end{array}$ \\
\hline & Dead n & & & & \\
\hline Provisional diagnosis & $(\%)$ & Alive n (\%) & & & \\
\hline Malignancy & $6(46.2)$ & $7(53.8)$ & & & \\
\hline Other diagnosis & $19(13.9)$ & $118(86.1)$ & 5.32 & $\begin{array}{l}1.61- \\
17.55\end{array}$ & 0.006 \\
\hline Gender & & & & & \\
\hline Male & $22(20.9)$ & $83(79.1)$ & & & \\
\hline Female & $3(6.8)$ & $41(93.2)$ & 3.62 & $\begin{array}{l}1.02- \\
12.80\end{array}$ & 0.046 \\
\hline $\begin{array}{l}\text { Uremia } \\
\text { Urea }>6.5 \mathrm{mmol} / \mathrm{L}\end{array}$ & $15(30.6)$ & $34(69.4)$ & & & \\
\hline Urea $=6.5 \mathrm{mmol} / \mathrm{L}$ & $4(6.6)$ & $57(93.4)$ & 6.28 & $\begin{array}{l}1.93- \\
20.49\end{array}$ & 0.002 \\
\hline $\begin{array}{l}\text { Glasgow coma scale } \\
\text { GCS }<15\end{array}$ & $7(41.2)$ & $10(58.8)$ & & & \\
\hline $\mathbf{G C S}=15$ & $18(13.5)$ & $115(86.5)$ & 4.47 & $\begin{array}{l}1.51- \\
13.25\end{array}$ & 0.007 \\
\hline
\end{tabular}


Case fatality rate of UGIB among study patients

Twenty-five patients out of 150 died giving a case fatality rate of $16.7 \%$. Death occurred more often among males [odds ratio (OR ) 3.62, 95\% confidence interval (CI) 1.02- 12.80, p-value $=0.046]$, among patients with a provisional diagnosis of malignancy (OR 5.32, 95\% CI 1.61- 17.55, p-value $=0.006)$, among patients with uremia (OR 6.13, 95\% CI 1.93-20.49, p-value 0.002) and among patients admitted with a GCS $<15$ (OR
4.47, 95\% CI 1.51-13.25, p-value $=0.007)$. See table 3 for these results. Using multivariate logistic regression analysis where potential confounders (gender, provisional diagnosis, uremia, and GCS) were controlled for, uremia was the only variable that remained significantly associated with the case fatality rate among study participants (Table 4). Patients with uremia were more likely to die than patients with normal urea levels (OR 5.4, 95\% CI 1.57-18.53, p-value 0.007).

Table 4. Multivariate analysis of factors associated with the case fatality rate among study participants $(\mathrm{n}=150)$

\begin{tabular}{|c|c|c|c|c|c|}
\hline \multirow[t]{2}{*}{ Variables } & & & OR & $95 \% \mathrm{CI}$ & \\
\hline & $\begin{array}{l}\text { Dead n } \\
(\%)\end{array}$ & Alive n (\%) & & & \\
\hline \multicolumn{6}{|l|}{ Gender } \\
\hline Male & $22(20.9)$ & $83(79.1)$ & & & \\
\hline Female & $3(6.8)$ & $41(93.2)$ & 1.54 & $0.36-6.63$ & 0.56 \\
\hline \multicolumn{6}{|l|}{ Provisional } \\
\hline \multicolumn{6}{|l|}{ Diagnosis } \\
\hline Malignancy & $6(46.2)$ & $7(53.8)$ & & & \\
\hline Other diagnosis & 19(13.9) & $118(86.1)$ & 3.9 & $0.8-19$ & 0.095 \\
\hline \multicolumn{6}{|l|}{ Uremia } \\
\hline Urea $>6.5 \mathrm{mmol} / \mathrm{L}$ & $15(30.6)$ & $34(69.4)$ & & & \\
\hline Urea $=6.5 \mathrm{mmol} / \mathrm{L}$ & $4(6.6)$ & $57(93.4)$ & 5.4 & $\begin{array}{l}1.57- \\
18.53\end{array}$ & 0.007 \\
\hline \multicolumn{6}{|c|}{ Glasgow coma scale } \\
\hline $\mathbf{G C S}<15$ & $7(41.2)$ & $10(58.8)$ & & & \\
\hline $\mathbf{G C S}=15$ & $18(13.5)$ & $115(86.5)$ & 2.22 & $0.56-8.79$ & 0.256 \\
\hline
\end{tabular}

\section{Survival analysis}

Survival analysis using the number of days in the hospital as the time to event (either death or date of discharge) was performed on a subset of the sample that had complete data $(n=140)$. Using the Wilcoxon test, a significant difference in the mean number of days was observed

Between patients who died and patients who were discharged $(p=0.0148)$. survival analysis for time to death versus time to discharge grouped by gender, urea sta- tus, GCS, and malignancy was performed. This analysis identified that the number of days in the hospital was significantly less for patients who died as compared to those who were discharged if the patients were male $(p$-value $=0.0098)$, had uremia $(p$-value $=0.0342)$, or had a provisional diagnosis of malignancy ( $\mathrm{p}$-value $=$ $0.0226)$. There was no significant difference in the survival curves for patients based of GCS, for female patients, for patients with normal urea level, and for patients with a diagnosis other than malignancy (Table 5 and Figure 2). 
Table 5. Survival analysis among patients $(n=140)$

\begin{tabular}{|c|c|c|c|c|c|c|}
\hline Variable & Group & Outcome & $\mathbf{N}$ & $\begin{array}{l}\text { Mean \# days } \\
\text { until event }\end{array}$ & Std. Error & p-value \\
\hline \multirow[t]{2}{*}{ Overall } & & Death & 20 & 5.05 & 1.27 & 0.0148 \\
\hline & & Discharged & 120 & 5.83 & 0.32 & \\
\hline \multirow[t]{4}{*}{ Gender } & Males & Death & 16 & 4.19 & 1.13 & 0.0098 \\
\hline & & Discharged & 82 & 5.65 & 0.36 & \\
\hline & Females & Death & 4 & 8.5 & 4.56 & 0.9300 \\
\hline & & Discharged & 38 & 6.24 & 0.69 & \\
\hline \multirow[t]{4}{*}{ Uremia } & Urea $(>6.5)$ & Death & 13 & 5.84 & 1.91 & 0.0342 \\
\hline & & Discharged & 32 & 5.75 & 0.56 & \\
\hline & Urea (normal) & Death & 2 & 6.00 & 0.00 & 0.8076 \\
\hline & & Discharged & 54 & 6.06 & 0.46 & \\
\hline \multirow[t]{4}{*}{ Diagnosis } & Malignancy & Death & 4 & 3.25 & 1.03 & 0.0226 \\
\hline & & Discharged & 11 & 7.27 & 1.19 & \\
\hline & Other & Death & 13 & 6.15 & 1.89 & 0.2974 \\
\hline & & Discharged & 94 & 5.77 & 0.38 & \\
\hline Glasgow & Low $\mathbf{G C S}=\mathbf{1 4}$ & Death & 8 & 4.75 & 2.55 & 0.0642 \\
\hline \multirow[t]{3}{*}{ Coma Scale } & & Discharged & 9 & 8.33 & 2.23 & \\
\hline & $\mathbf{G C S}=15$ & Death & 12 & 5.25 & 1.38 & 0.2374 \\
\hline & & Discharged & 111 & 5.63 & 0.30 & \\
\hline
\end{tabular}

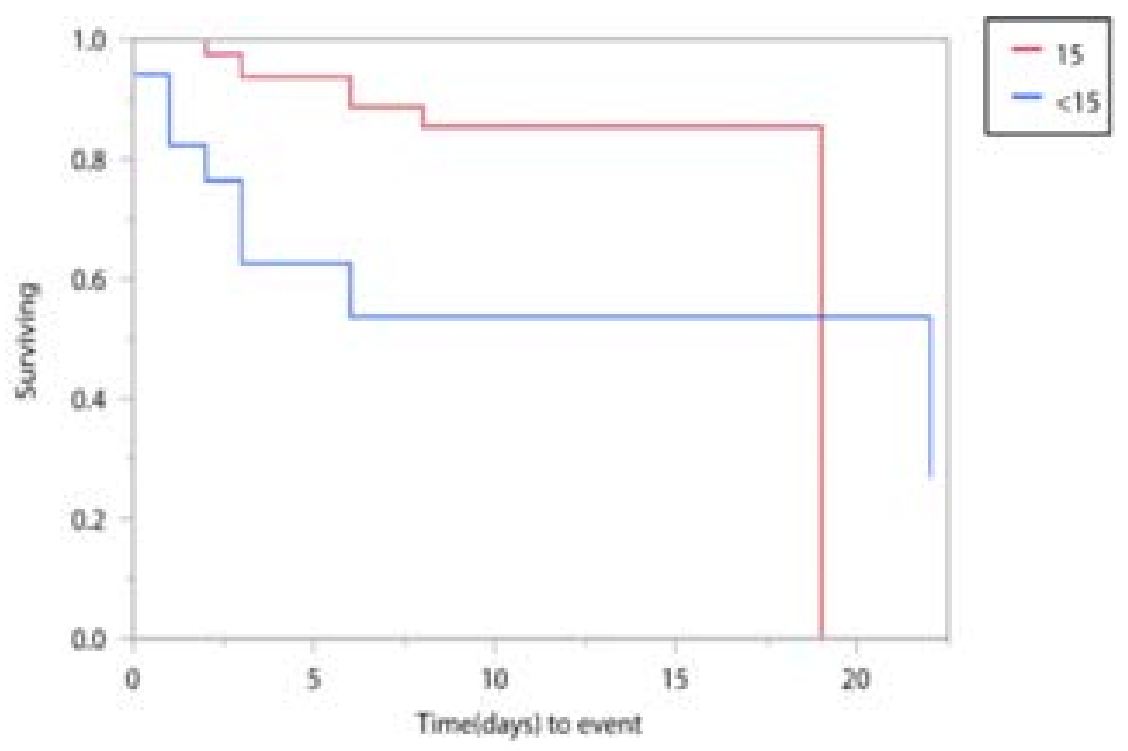

Figure 2. Kaplan-Meier survival curve for patients with low $(<15)$ and nomal (15) Glascow Coma Scale (GCS) 


\section{Discussion}

UGIB is one of the most common emergencies in gastroenterology and it is a life threatening condition. Although mortality and morbidity has improved in the developed world, the world-wide trend of mortality due to UGIB over the last decade has not changed; varying between 3 and $14 \%{ }^{3}$. Since UGIB is a life threatening condition, decision makers in health care settings should focus on reducing risk factors of UGIB.

The prevalence of UGIB symptoms was $20.3 \%$ among study patients in the gastrointestinal and hepathology service of this large tertiary care facility in Uganda. This high prevalence is not surprising given the high prevalence of risk factors UGIB. Apica et $\mathrm{al}^{11}$ found that $36.5 \%$ of patients with liver cirrhosis in Mulago hospital presented with UGIB. There is also a high prevalence of H.pylori infection (up to $73.5 \%$ in patients undergoing endoscopy) at Mulago hospital which could be responsible for peptic ulcer disease (PUD) and gastritis $^{12}$. The prevalence of adults with viral hepatitis, a risk factor for cirrhosis, portal hypertension, and variceal bleeding, was estimated by detection of $\mathrm{HBcAb}$ in a national sero-survey in Uganda to be of $52.3 \%$ (95\% CI: $51.0-53.6)^{13,14}$. This prevalence is high compared to that found in southwestern Nigeria (6.9\%) in 2006 and in Morocco in 2008 6,15.

The majority of the patients in our study were young males aged 40 years or less. These finding are similar to other studies performed in Tanzania ${ }^{17,18}$. The observed age distribution could be reflective of the overall Ugandan population, where $21.2 \%$ of the Ugandan population was found to be between 15-24 years and 25.5\% between 25-54 years (Uganda Demographics Profile of 2013, Uganda bureau of statistics). The male gender predisposition could be a result of disparity in distribution of the etiological factors that influence UGIB in both genders such as gastritis, PUD and liver cirrhosis caused by viral hepatitis and alcohol abuse ${ }^{14,16}$.

Gastritis (59/150, 39.3\%) was the most common clinical diagnosis of UGIB followed by bleeding esophageal varices $(26 / 150 ; 17.3 \%)$ and PUD (24/150; 16\%). A similar distribution of causes was found in Nigeria by Oladimeji AA et al who found that erosive antral gastritis was the most common cause of UGIB followed by PUD and varices ${ }^{19}$. The high frequency of gastritis and PUD may be reflective of the high prevalence of H.pylori at Mulago hospital, since H. pylori is among the most common causes of gastritis and PUD ${ }^{20}$. In addition, Uganda, similarly to Nigeria, is among the countries with the highest prevalence of H.pylori included gastritis $^{19,21}$.

Among the subset of patients with endoscopy results $(n=38)$, the most common diagnoses were variceal bleeding, followed by PUD and gastritis. In Northern Uganda at Lacor Hospital in Gulu, a similar trend was reported for the endoscopic causes of UGIB10. In two other studies, one in Egypt and one in Tanzania, it was found that the distribution of causes of UGIB was similar to the findings in Uganda with bleeding varices being the most common followed by PUD ${ }^{18,22}$.

The differences we observed between the clinical and endoscopic diagnosis can be expected as shown by a study in Nigeria by EA Agbakwuru et al. ${ }^{6}$. In this Nigerian study, the authors aimed to evaluate the pattern and validity of clinical diagnosis of upper gastrointestinal diseases. They found that, in general, there is poor agreement between clinical and endoscopic diagnoses ${ }^{6}$.

The mortality rate in our study was high (16.7\%) compared to the worldwide trend of UGIB mortality which is between $3-14 \% \%^{3}$, but similar to other African studies (mortality rates of $17 \%$ and $17.9 \% 0^{23}$ ). Two African studies $^{19,24}$ that report lower mortality rates ( $5 \%$ and $4.5 \%$ ) only included patients that underwent endoscopy. The high mortality rate in our study may be reflective of the relatively low income of our study participants in which less than $25 \%$ could afford UGI endoscopy. UGI endoscopy leads to definitive diagnoses and allows for proper treatment of some causes of UGIB. Furthermore, most patients in our study had difficulty paying for medication that may be used to prevent or to treat some causes of UGIB.

The mortality rate in our study was significantly higher among males, (OR 3.62, 95\% CI 1.02-12.80, p-val$\mathrm{ue}=0.046$ ), among patients with a provisional diagnosis of malignancy (OR 5.32, 95\% CI 1.61- 17.55, p-value= 0.006), among patients admitted with uremia (OR 6.13, 95\% CI 1.93-20.49, p-value 0.002) and among patients with GCS less than 15 (OR 4.47, 95\%CI 1.51-13.25, p-value $=0.007)$. the male gender predisposition to death was previously reported ${ }^{25}$ and may be explained by males seeking health care later than females ${ }^{26}$. The high mortality in patients admitted with a provisional diagnosis of malignancy may be explained by the fact that symptoms of UGIB are alarm symptoms of GI malignancies. These symptoms may indicate an advanced malignancy with poor prognosis. 
This was reported by Jaka et al in Tanzania where malignancy was also among factors associated with mortality ${ }^{17}$. A GCS of $<15$ was reported to be a statistically independent predictor of mortality in a study among patients admitted with bleeding esophageal varices in ICU in a teaching hospital in the USA ${ }^{27}$. Uremia may worsen the bleeding due to the action of urea on the gastro intestinal mucosa and due to platelet dysfunction. This may prolong the bleeding among patients with uremia creating vicious cycle which can predispose to bad outcome ${ }^{28}$.

Survival analysis indicates that the first 5-6 days after being admitted to the GI ward are critical to determine the outcome of a patient. Furthermore, survival analysis by groups confirmed poorer prognosis for patients who were male, had uremia and who were diagnosed with malignancy.

\section{Limitations}

This study has a number of limitations. Firstly, there were some missing results and the number of endoscopies to definitively identify the causes of UGIB was limited. Secondly, history of use of NSAIDs and/or warfarin was not recorded and patients with liver disease or coagulopathy were excluded. Finally, history of blood transfusion for the presenting UGIB was not considered. Despite these limitations, the study has a number of strengths since it is the first known study to describe outcomes of UGIB in to identify predictors for in-hospital mortality in a resource limited setting. This study adds to the body of knowledge of gastrointestinal afflictions in sub-Saharan Africa.

\section{Conclusion}

The prevalence of symptoms and the case fatality rate of UGIB are high in Mulago hospital.

The majority of patients are young men. The most common causes of UGIB are esophageal varices, gastritis and PUD. Focusing more on male patients, patients with malignancy, and with uremia may reduce the mortality due to UGIB in Mulago hospital. Educating the population, especially the male population on risk factors, prevention and early consultation may reduce the mortality due to UGIB.

\section{References}

1. Laine L. Upper gastrointestinal bleeding. Clinical Update. 2007;14(3):1-4.

2. Esrailian E, Ian M, Gralnek IM. Nonvariceal upper gastrointestinal bleeding: epidemiology and diag-
nosis.Gastroenterol Clin N Am. 2005;34:589-605. doi: 10.1016/j.gtc.2005.08.006.

3. Sostres C, Lanas A. Epidemiology and Demographics of Upper Gastrointestinal Bleeding: Prevalence, Incidence, and Mortality. Gastrointestinal Endoscopy Clinics of North America. 2011;21(4):567-81.

4. Taefi A, Cho WK, Nouraie M. Decreasing Trend of Upper Gastrointestinal Bleeding Mortality Risk Over Three Decades. Digestive Diseases and Sciences. 2013;58(10):2940-8.

5. Kasem AM, Kamal T, Chandra NN, Dayoub I, Munyira H, El-Hasani S. Management of acute upper gastrointestinal bleeding in a district hospital. Journal of Laparoendoscopic \& Advanced Surgical Techniques. 2006;16(4):355-61.

6. Agbakwuru E, Fatusi A, Ndububa D, Alatise O, Arigbabu O, Akinola D. Pattern and validity of clinical diagnosis of upper gastrointestinal diseases in south-west Nigeria. African Health Sciences. 2006;6(2):98-103.

7. Mustapha S, Ajayi N, Shehu A. Aetiology of upper gastrointestinal bleeding in north-eastern nigeria: a retrospective endoscopic study. The Internet Journal of Third World Medicine. 2009;8(2).

8. Suba MR, Ayana SM, Mtabho CM, Kibiki GS. The aetiology, management and clinical outcome of upper gastrointestinal bleeding among patients admitted at the Kilimanjaro Christian Medical Centre in Moshi, Tanzania. Tanzania Journal of Health Research. 2010;12(4):286-9. 9. Ombeva O, Ndeezi G, Mugalu J. Upper GI bleeding among neonates admitted to Mulago Hospital, Kampala, Uganda: a prospective cohort study. African Health Sciences. 2013;13(3):741-7.

10. Alema N. Endoscopic Findings in Upper Gastrointestinal Bleeding at Lacor Hospital in Gulu, Northern Uganda. East and Central African Journal of Surgery. 2012;17(1):94-7.

11. Apica B, Ocama P, Seremba E, Opio K, Kagimu M. Decompensated cirrhosis-related admissions in a large urban hospital in Uganda: prevalence, clinical and laboratory features and implications for planning patient management. African Health Sciences. 2014;13(4):927-32.

12. Ocama P. Testing for Helicobacter pylori status among patients undergoing diagnostic endoscopy in Mulago and Nsambya hospital Mmed thesis. 2001.

13. Obot IS, Room R. Alcohol, gender and drinking problems: perspectives from low and middle income countries: World Health Organization; 2005.

14. Bwogi J, Braka F, Makumbi I, Mishra V, Bakamutumaho B, Nanyunja M, et al. Hepatitis B infection is highly endemic in Uganda: findings from a national serosurvey. African Health Sciences. 2009;9(2). 
15. Timraz A, Khannoussi W, Ajana F, Essamri W, Benelbarhdadi I, Afifi R, et al. Acute upper gastro-intestinal bleeding in morocco: what have changed? ISRN Gastroenterology. 2011;2011.

16. Shimizu I, Kamochi M, Yoshikawa H, Nakayama Y. Gender Difference in Alcoholic Liver Disease. 2012 201201-11.

17. Jaka H, Koy M, Liwa A, Kabangila R, Mirambo M, Scheppach W, et al. A Fibreoptic endoscopic study of upper gastrointestinal bleeding at Bugando Medical Centre in northwestern Tanzania: A retrospective review of 240 cases. BMC Research Notes. 2012;5(1):200.

18. Suba M, Ayana SM, Mtabho CM, Kibiki GS. The aetiology, management and clinical outcome of upper gastrointestinal bleeding among patients admitted at the Kilimanjaro Christian Medical Centre in Moshi, Tanzania. Tanzania Journal of Health Research. 2010;12(4).

19. Oladimeji AA, Temi AP, Ebenezer A, Adekunle SOA, Olatayo AA, Abayomi AM. Aetiology and Management Outcome of Upper Gastrointestinal Bleeding in Adult Patients Presenting at Ekiti State University Teaching Hospital, Ado-Ekiti, Nigeria.

20. Segamwenge I. The utility of the stool antigen test in predicting helicobacter pylori associated disease among patients with dyspepsia at Mulago Hospital. Mmed thesis. 2010.

21. Crooks C, Card T, West J. Reductions in 28-Day Mortality Following Hospital Admission for Upper Gastrointestinal Hemorrhage. Gastroenterology.141(1):62-70.
22. Gado AS, Ebeid BA, Abdelmohsen AM, Axon AT. Clinical outcome of acute upper gastrointestinal hemorrhage among patients admitted to a government hospital in Egypt. Saudi Journal of Gastroenterology: official Journal of the Saudi Gastroenterology Association. 2012;18(1):34. 23. Mustapha S, Ajayi N, Shehu A. Aetiology Of Upper Gastrointestinal Bleeding In North-Eastern Nigeria: A Retrospective Endoscopic Study. Internet Journal of Third World Medicine. 2009;8(2).

24. Lule G, Obiero E, Ogutu E. Factors that influence the short term outcome of upper gastrointestinal bleeding at Kenyatta National Hospital. East African Medical Journal. 1994;71(4):240-5.

25. Button LA, Roberts SE, Evans PA, Goldacre MJ, Akbari A, Dsilva R, et al. Hospitalized incidence and case fatality for upper gastrointestinal bleeding from 1999 to 2007: a record linkage study. Alimentary Pharmacology \& Therapentics. 2011;33(1):64-76.

26. Galdas PM, Cheater F, Marshall P. Men and health help-seeking behaviour: literature review. Journal of $A d$ vanced Nursing. 2005;49(6):616-23.

27. Lee H, Hawker FH, Selby W, McWilliam DB, Herkes RG. Intensive care treatment of patients with bleeding esophageal varices: Results, predictors of mortality, and predictors of the adult respiratory distress syndrome. Critical Care Medicine. 1992;20(11):1555-63.

28. Shirazian S, Radhakrishnan J. Gastrointestinal disorders and renal failure: exploring the connection. Nat Rev Nephrol. 2010 08//print;6(8):480-92. 